\title{
A follow-up study of the variations in the body composition of karate athletes
}

\begin{abstract}
We monitored body composition variations in nine elite karateists during a 3-year period $\left(\mathrm{T}_{1}, \mathrm{~T}_{2}, \mathrm{~T}_{3}\right)$. Arm circumference (AC) and six skinfolds were measured. Arm muscle circumference (AMC) and area (AMA) were then calculated. Fat mass (FM) was calculated using the DurninWomersley, Sloan-Weir (S-W), Katch-McArdle and Lohman equations. The only significant increase regarded the AC, AMC and AMA measurements between $\mathrm{T}_{1}$ and $\mathrm{T}_{2}$. The time course of the predicted FM amount using the different equations was the same. In particular, the S-W equation did not seem to reflect the modifications in the amount of FM as evidenced by the total sum of the six skinfolds. Our subjects were characterized by a substantial uniformity in body composition parameters measured in this 3-year follow-up study.
\end{abstract}

Key words Karate $\cdot$ Follow-up study $\cdot$ Skinfolds $\cdot$ Body composition

M. Giampietro • I. Bertini (凶)

Human Nutrition Unit, Department of Neurosciences

University of Tor Vergata, Via Montpellier 1, I-00133 Rome, Italy

A. Pujia

Faculty of Medicine and Surgery, University of Catanzaro, Italy

\section{Introduction}

In many sports where the result is greatly influenced by body weight of athletes competing in well-defined weight categories (gymnastics, running, boxing, martial arts, etc.), acute weight loss before competition or long-term weight fluctuations are typically achieved through restricted food and fluid intake, saunas, and intense exercise [1]. In our study, we monitored body composition variations in nine elite karateists during a 3-year period $\left(\mathrm{T}_{1}, \mathrm{~T}_{2}, \mathrm{~T}_{3}\right)$.

\section{Subjects and methods}

We examined nine male athletes, of a high competitive level, during a 3-year period $\left(\mathrm{T}_{1}, \mathrm{~T}_{2}, \mathrm{~T}_{3}\right)$.

\section{Anthropometric measurements}

The following measurements were taken by one physician on the left side of the body according to conventional procedures [2]: weight, height, arm circumference, and six skinfolds (biceps, triceps, subscapular, suprailiac, abdominal and thigh) using a Harpenden plicometer. The anthropometric indices were then calculated as follows: body mass index $(\mathrm{BMI})=$ weight $(\mathrm{kg}) /$ height $^{2}\left(\mathrm{~m}^{2}\right)$; arm muscle circumference $(\mathrm{AMC}, \mathrm{cm})$ and area $\left(\mathrm{AMA}, \mathrm{cm}^{2}\right)$ were calculated on the basis of the Gurney and Jelliffe equations [3].

Body composition measurements

To convert plicometric data into the respective body densities, we used the equations of Durnin-Womersley (D-W) [4], Sloan-Weir (S-W) [5], Katch-McArdle (K-M) [6], and Lohman (L) [7]. Subsequently, we converted body densities into FM percentages using Brozek's formula [8]. The FFM quantity was obtained as the difference between body weight $(\mathrm{kg})$ and $\mathrm{FM}(\mathrm{kg})$. 
Statistical analysis

The ANOVA test for repeated measures was used to determine statistically significant differences among the three measurements. Significance was set at $p<0.05$.

\section{Results}

The age of the subjects was $22.6 \pm 2.3$ years (mean \pm SD) and height was $179.9 \pm 7.4 \mathrm{~cm}$ at the time of the first measurement (Table 1). Body weight and BMI variations were not statistically significant. Concerning plicometric data, we did not note substantial differences during the 3-year follow-up.
The AC measurement showed a significant increase from $\mathrm{T}_{1}$ $(28.2 \pm 1.5 \mathrm{~cm})$ to $\mathrm{T}_{2}(29.2 \pm 2.0 \mathrm{~cm} ; p<0.05)$ and $\mathrm{T}_{3}(29.6$ $\mathrm{cm} \pm 2.2 ; p<0.01)$. The difference measured between $\mathrm{T}_{2}$ and $\mathrm{T}_{3}$ was not significant. In the same way, AMC and AMA showed a significant increase (Table 1).

No significant changes were observed in FM and FFM amount during the 3 -year period (Table 2). The time course of the predicted FM and FFM amounts using the different equations was the same. In particular, the sum of the two skinfolds, based on the S-W equation, did not seem to reflect the modifications in the amount of FM as evidenced by the total sum of the six skinfolds. Generally, the D-W equation tends to overestimate FM quantity with respect to the $\mathrm{S}-\mathrm{W}$ formula or other equations more specific for athletic populations (K-M and L).

Table 1 Variations in anthropometric parameters during the 3-year follow-up $\left(\mathrm{T}_{1}, \mathrm{~T}_{2}, \mathrm{~T}_{3}\right)$. Values are mean (SD)

\begin{tabular}{|c|c|c|c|}
\hline & $\mathrm{T}_{1}$ & $\mathrm{~T}_{2}$ & $\mathrm{~T}_{3}$ \\
\hline Age, years & $22.6(2.3)$ & & \\
\hline Height, cm & $179.9(7.4)$ & & \\
\hline Weight, kg & $71.2(8.7)$ & $71.5(9.6)$ & $72.4(9.5)$ \\
\hline BMI, $\mathrm{kg} / \mathrm{m}^{2}$ & $22.0(1.6)$ & $22.1(2.0)$ & $22.3(1.8)$ \\
\hline \multicolumn{4}{|l|}{ Skinfolds, mm } \\
\hline Biceps & $3.5(1.0)$ & $3.6(1.0)$ & $3.8(1.1)$ \\
\hline Triceps & $7.8(2.1)$ & $7.5(2.4)$ & $7.6(2.0)$ \\
\hline Subscapular & $8.8(1.7)$ & $8.5(1.1)$ & $9.1(2.0)$ \\
\hline Suprailiac & $5.6(1.6)$ & $6.6(2.4)$ & $8.0(4.7)$ \\
\hline Thigh & $10.3(2.7)$ & $10.0(3.2)$ & $9.8(3.7)$ \\
\hline Abdominal & $6.4(2.6)$ & $6.1(1.5)$ & $8.5(4.4)$ \\
\hline $\mathrm{AC}, \mathrm{cm}^{*}$ & $28.2(1.5)$ & $29.2(2.0)$ & $29.6(2.2)$ \\
\hline $\mathrm{AMC}, \mathrm{cm}^{*}$ & 25.7 (1.6) & $26.8(1.8)$ & $27.2(2.0)$ \\
\hline $\mathrm{AMA}, \mathrm{cm}^{2 * *}$ & $52.7(6.6)$ & $57.4(7.6)$ & $59.0(8.7)$ \\
\hline
\end{tabular}

${ }^{*} p<0.05, \mathrm{~T}_{1}$ vs. $\mathrm{T}_{2} ; * * p<0.01, \mathrm{~T}_{1}$ vs. $\mathrm{T}_{3} . A C$, arm circumference; $A M C$, arm muscle circumference; $A M A$, arm muscle area

Table 2 Variations in body composition parameters during the 3-year follow-up $\left(\mathrm{T}_{1}, \mathrm{~T}_{2}, \mathrm{~T}_{3}\right)$. Values are mean (SD)

\begin{tabular}{|c|c|c|c|}
\hline & $\mathrm{T}_{1}$ & $\mathrm{~T}_{2}$ & $\mathrm{~T}_{3}$ \\
\hline \multicolumn{4}{|l|}{$\mathrm{FM}, \mathrm{kg}$} \\
\hline D-W & $8.0(2.2)$ & $8.2(2.6)$ & $9.0(3.2)$ \\
\hline S-W & $6.6(1.7)$ & $6.5(2.2)$ & $6.8(2.6)$ \\
\hline $\mathrm{K}-\mathrm{M}$ & $5.9(1.5)$ & $5.7(1.7)$ & $6.4(2.3)$ \\
\hline $\mathrm{L}$ & $6.0(1.7)$ & $5.8(1.7)$ & $6.7(2.6)$ \\
\hline \multicolumn{4}{|l|}{ FFM, kg } \\
\hline D-W & $63.2(7.0)$ & $63.3(7.3)$ & $63.4(7.0)$ \\
\hline S-W & $64.6(7.9)$ & $65.0(8.1)$ & $65.6(7.6)$ \\
\hline $\mathrm{K}-\mathrm{M}$ & $65.3(7.8)$ & $65.8(8.2)$ & $65.9(7.9)$ \\
\hline $\mathrm{L}$ & $65.2(7.7)$ & $65.7(8.2)$ & $65.7(7.8)$ \\
\hline \multicolumn{4}{|c|}{ Sum of skinfolds, mm } \\
\hline Total & $42.5(9.5)$ & $42.2(10.1)$ & $46.7(16.1)$ \\
\hline D-W & $25.7(5.2)$ & $26.2(6.0)$ & $28.5(8.9)$ \\
\hline S-W & $19.1(3.9)$ & $18.5(4.1)$ & $18.9(5.0)$ \\
\hline $\mathrm{K}-\mathrm{M}$ & $23.1(5.4)$ & $22.0(4.2)$ & $25.2(7.7)$ \\
\hline $\mathrm{L}$ & $23.1(5.4)$ & $22.0(4.2)$ & $25.2(7.7)$ \\
\hline
\end{tabular}

$F M$, fat mass; FFM, fat-free mass; Total, sum of skinfolds and sum of skinfolds calculated according to the different equations; $D$ - $W$, Durnin-Womersley; $S$ - $W$, Sloan-Weir; $K$ - $M$, Katch-McArdle; $L$, Lohman 
The sum of skinfolds calculated according to the different equations did not show significant variations during the 3-year period (Table 2).

\section{Discussion}

In many weight-limited sports, such as karate, athletes practise restricted food and fluid intake, saunas, and intense exercise to reach a body weight lower than the physiological one (according to age, sex, body size and composition). In this way, they can compete in a lower weight category and take advantage of a better arm and leg length with respect to their opponents. In our study, we monitored anthropometric and body composition variations in nine elite karateists during a 3-year period.

Results showed a substantial stability in the values of the body weight and the six skinfold thicknesses measured. Arm circumference was the only parameter that increased significantly between $T_{1}$ and $T_{2}$. This variation, besides the stability of the triceps skinfold, led to substantial modifications in AMC and AMA. AMA is considered a good indicator of the total body muscle mass; however, in our study, variations in AMA values did not correspond to FFM values. The reason of this result could be that anthropometry does not represent a direct measurement of individual muscle mass and that the accuracy of AMA measurements in long-term muscle mass prediction must be verified.

Concerning the different plicometric equations, as already reported in other publications, the DurninWomersley formula tends to overestimate FM quantity with respect to other general equations (e.g., Sloan-Weir equation) or more athletic-specific equations like that of KatchMcArdle and Lohman. Moreover, the time course of FM quantity, based on the sum of skinfolds, during the follow- up study is not the same for the four equations. In particular, the Sloan-Weir equation, based on the measurement of only two skinfold thicknesses, does not reflect the small variations in FM as expected from the time course of the total sum of six skinfolds. Thus, the Sloan-Weir equation, although developed on a group of healthy subjects, does not seem to be valid in longitudinal studies when applied to individual athletic subjects.

\section{References}

1. De Lorenzo A, Bertini I, Candeloro N, Iacopino L, Andreoli A, Van Loan MD (1998) Comparison of different techniques to measure body composition in moderately active adolescents. Br J Sports Med 32:215-219

2. Lohman TG, Roche AF, Martorell R (1988) Anthropometric standardization reference manual. Human Kinetics Books, Champaign

3. Gurney JM, Jelliffe DB (1973) Arm anthropometry in nutritional assessment: nomogram for rapid calculation of muscle circumference and cross-sectional muscle and fat areas. Am J Clin Nutr 26:912-915

4. Durnin JVGA, Womersley J (1974) Body fat assessed from total body density and its estimation from skinfolds thickness: measurements on 481 men and women aged from 16 to 72 years. Br J Nutr 32:77-97

5. Sloan AW, Weir JB (1970) Nomograms for prediction of body density and total body fat from skinfold measurements. J Appl Physiol 28:221-222

7. Lohman TG (1981) Skinfolds and body density and their relation to body fatness. A review. Hum Biol 53:181-225

6. Katch FI, McArdle WD (1973) Prediction of body density from simple anthropometric measurements in college age men and women. Ann Hum Biol 45:445-454

8. Brozek J, Grande F, Anderson JT, Keys A (1963) Densitometric analysis of body composition: revision of some quantitative assumptions. Ann N Acad Sci 110:113-140 